\title{
Richard Bright (1789-1858) and his contributions to the understanding of hydrocephalus
}

\author{
James Tait Goodrich
}

Published online: 23 December 2009

(C) Springer-Verlag 2009

Richard Bright (1789-1858), the eponymous discoverer of "Bright's disease" (nonsuppurative nephritis, edema of renal origin) was among the first physicians to integrate the hospital course of disease into a detailed pathological examination along with laboratory testing all these findings and then correlated them with his thorough postmortem findings [1]. This last concept was clearly illustrated in his studies on kidney diseases, i.e., "Bright's disease" or a dropsy of renal origin. Unfortunately, modern scholars and others have failed or at least lost interest in giving Bright his true due for superb medicopathological research in other medical subjects [2].

In a three-volume pathological atlas, Bright presented numerous other outstanding contributions to general pathology, nephrology, as well as neuropathology. One of Bright's most important contributions to neuropathology was on hydrocephalus. Bright provided several case illustrations along with his clinical presentations: All are meticulously hand-colored with his usual extraordinary attention to detail. In these illustrations, Bright takes his clinical observations a further step forward by providing visually beautiful medical illustrations to illustrate and thereby enhance the understanding of his cases. In a section of volume II are a series of case reports dealing with a series of neuropathological problems. I would like to focus on one of his cases, a patient named James Cardinal. Bright

J. T. Goodrich ( $\bowtie)$

Division of Pediatric Neurosurgery,

Leo Davidoff Department of Neurological Surgery,

Children's Hospital at Montefiore, Montefiore Medical Center,

Albert Einstein College of Medicine,

111 East 210th Street,

Bronx, NY 10467, USA

e-mail: James.Goodrich@einstein.yu.edu gives a clear description of a now adult patient with slowly progressive hydrocephalus. When Mr. Cardinal first presented to Bright as a patient at Guy's Hospital, his head was "enormous" and his clinical state was described as "deteriorating". Despite his large head size, Mr. Cardinal had been relatively functional with a reasonable speech and was able to walk independently. Mentation was "dull" but he could communicate his thoughts.

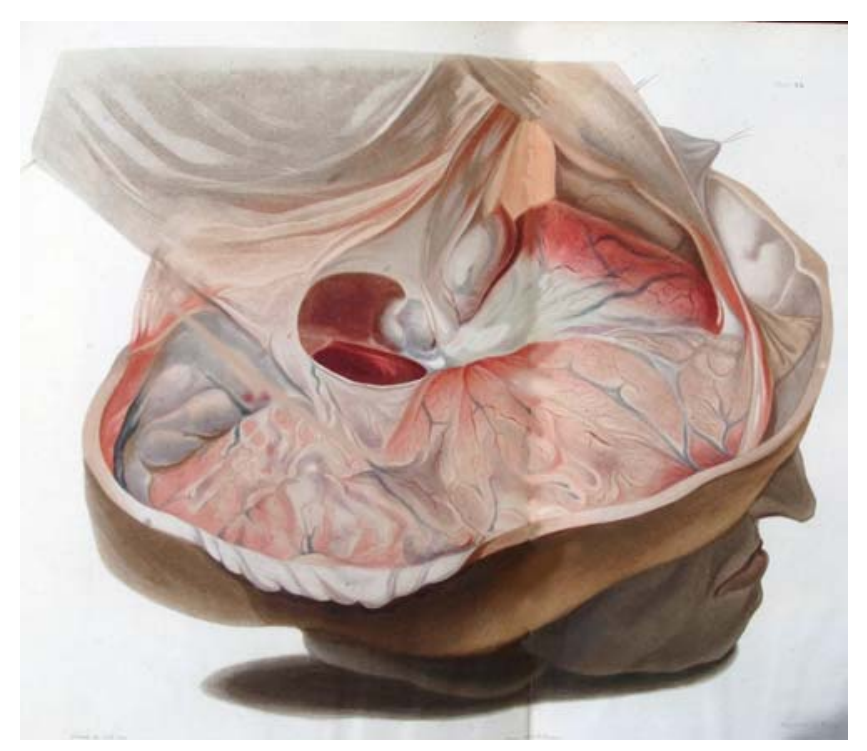

Fig. 1 A hand-colored postmortem artistic rending of James Cardinal showing severe ventricular dilatation. This illustration was originally done in gray tones and then hand water-colored (aquatints). The colors are vibrant and brilliant and clearly reflect the underlying pathology as seen and described by Richard Bright. What is impressive to remember is that these illustrations were typically hand-colored by nonmedical, low-paid craftsman, not physicians (Plate XXXIV). This figure is used as cover illustration 


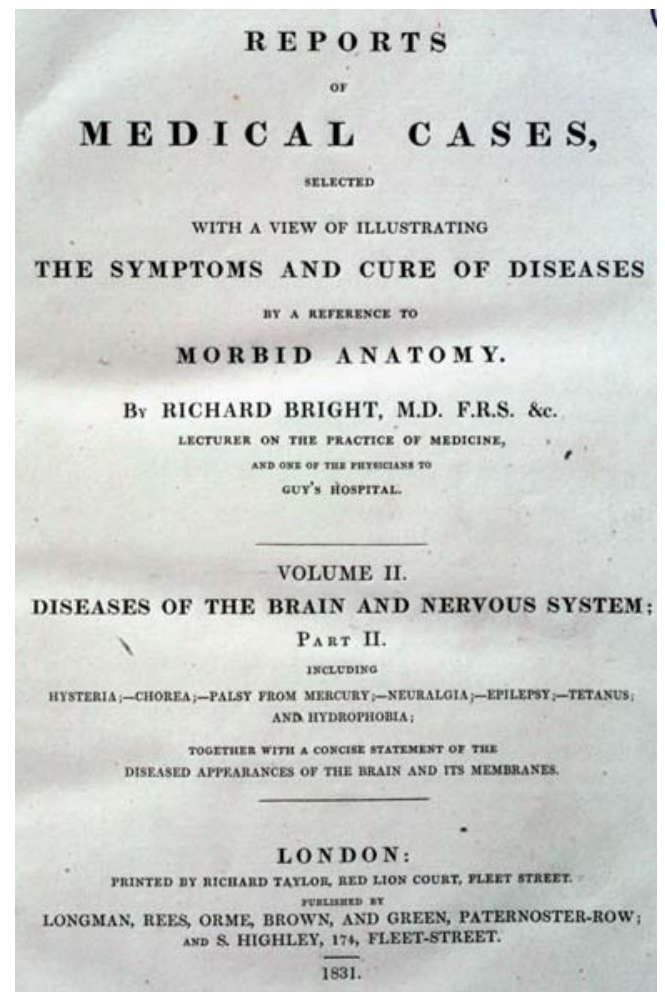

Fig. 2 Title page from Bright's work from the second volume, which deals with the diseases of the brain and nervous system. Within this remarkable atlas are a number of elegant hand-colored illustrations showing various brain pathology. The cases include apoplexy, brain hemorrhage, a pontine brain glioma, basilar artery atheroma, and what looks to be a an illustration of a glioblastoma

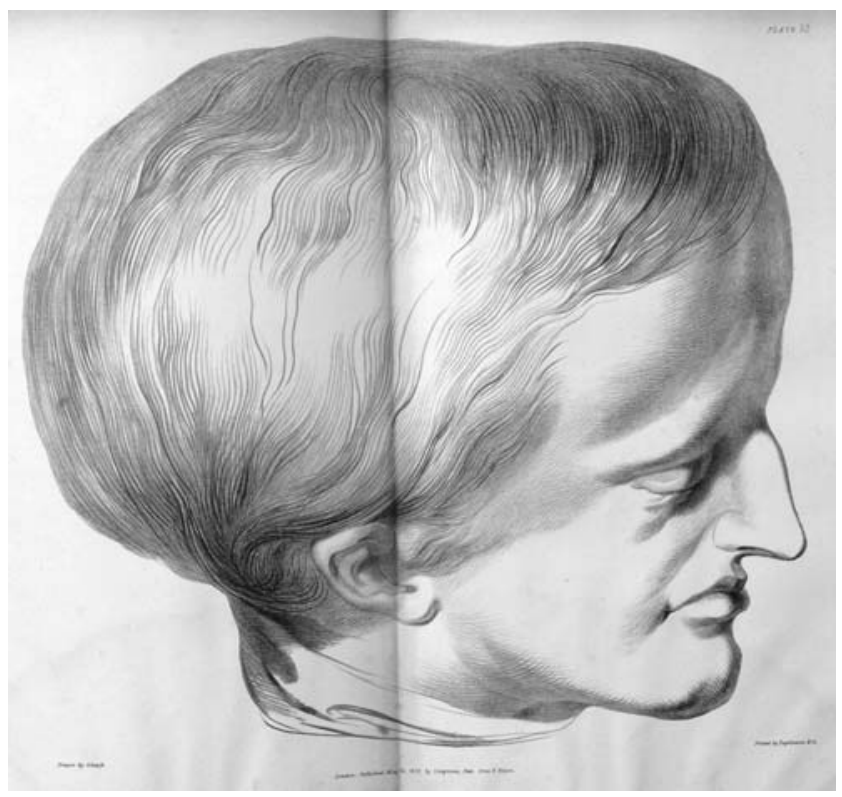

Fig. 3 A drawing of James Cardinal showing the cephalocranial dysmorphology of his head secondary to the long-standing hydrocephalus (Plate XXXIII)

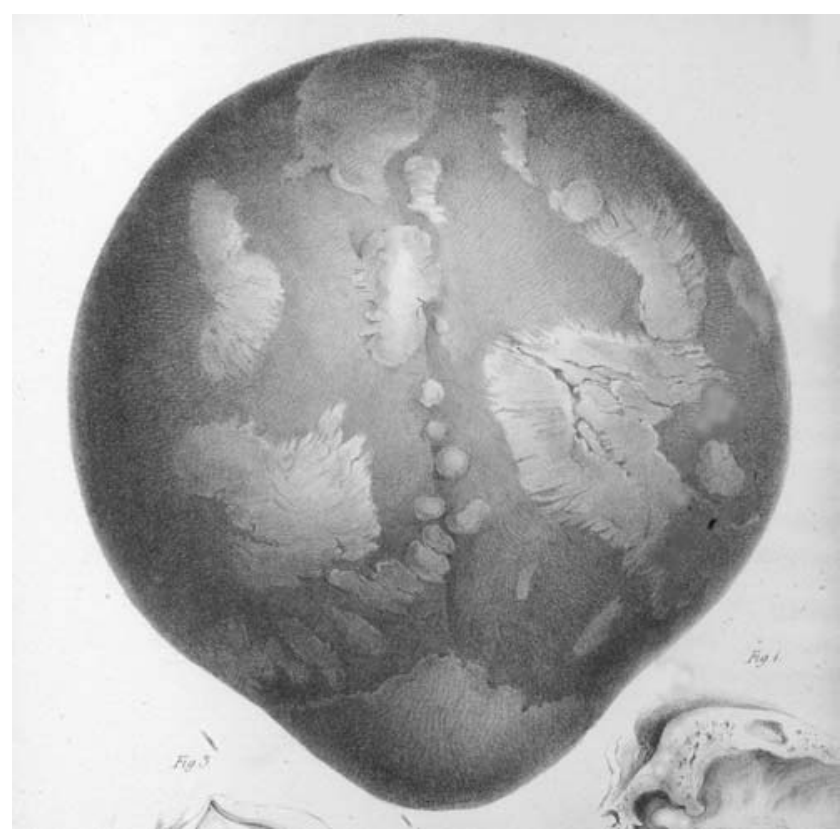

Fig. 4 The skull surface anatomy of a child with hydrocephalus in whom Bright points out the unusual ossification of the skull - what he describes as "ossa triquetra" that have formed in the spaces of the normal bone (Plate XXXII)

Dr. Bright includes several illustrations of the patient from his postmortem findings, one in brilliant handcolored aquatint and the other two in gray monotone. In these illustrations, Bright clearly displays the pathology of hydrocephalus and the dilated ventricles. Treatment at this time rarely involved surgery as the morbidity, and mortality in treating hydrocephalus was nearly $100 \%$. Treating physicians were forced to resort to use of diuretics, caustics, bleeding, blisters, colonic lavages, and the occasional blood sucking leech. The outcome in progressive hydrocephalus was always death. It is interesting to reflect back on our historical medical brethrens and review what they did in treatment of various disorders. Unfortunately the "modern" treatment of hydrocephalus did not evolve until the mid-twentieth century when various cerebrospinal fluid diversion devices were introduced.

Presented here (Figs. 1, 2, 3, and 4) is the case of James Cardinal, elegantly illustrated and described by Dr. Bright who had a contemporary and unusually clear understanding of the anatomical findings in of hydrocephalus.

\section{References}

1. Bright R (1827-1831) Reports of medical cases, selected with a view of illustrating the symptoms and cure of diseases by a reference to morbid anatomy. Longmans, London (In three volumes)

2. Wallis F, Miller P (eds) (2004) 75 books from the Osler Library. Osler Library, McGill University, Montreal, pp 58-59 